\title{
Errata: Properties of a Three-Dimensional Poisson-Voronoi Tesselation: A Monte Carlo Study
}

S. Kumar, S. K. Kurtz, J. R. Banavar, and M. G. Sharma

Received October 23, 1992

1. Page 526, footnote 5

$$
d\left(\log _{e} x\right) \text { instead of } d x .
$$

2. Page 540, paragraph 2, line 3

$$
\log _{e} x_{50}=2.7226 \text { instead of } x_{50}=2.7226
$$

3. Page 547, paragraph 2, line 4

$$
\log _{e} x_{50}=-0.0735 \text { instead of } x_{50}=-0.0735
$$

4. Page 548 , paragraph 4 , line 3

$$
\log _{e} x_{50}=1.7436 \text { instead of } x_{50}=1.7436
$$

${ }^{1}$ This paper appeared in J. Stat. Phys. 67:523-551 (1992). 